\title{
Prion Disease
}

National Cancer Institute

\section{Source}

National Cancer Institute. Prion Disease. NCI Thesaurus. Code C128346.

A transmissible, infectious disease that is caused by a protein that is able to induce abnormal folding of normal cellular proteins, leading to characteristic spongiform brain changes, which are associated with neuronal loss without an inflammatory response. Such disorders have typically long incubation periods, but are then generally rapidly progressive and are uniformly fatal. 